\title{
Partners fall out over supercomputer bid
}

San Diego. A split has appeared in the academic/industrial partnership that has operated the San Diego Supercomputer Center for a decade about competition for a new grant from the US National Science Foundation (NSF).

The top three scientific administrators at the centre, which is run jointly by the company General Atomics (GA) and the University of California at San Diego (UCSD), have already resigned, and more key staff are thought to be about to leave.

NSF officials are monitoring the unprecedented strife closely because of concern that the centre might lose more staff. If so, it may be unable to fulfil federal contract obligations for the facility, which is one of four national NSF-funded supercomputer centres.

The NSF funds go to GA, a privately owned company involved primarily in nuclear research development, which employs the staff responsible for running the supercomputers. The computers themselves are housed in a building on UCSD's campus.

Differences in philosophy have led UCSD and GA to submit competing proposals for the next round of NSF funding for such centres, beginning in October 1997. This competition for NSF funding is designed to make supercomputers a more widely usable and diverse scientific asset.

The NSF's National Science Board does not want the $\$ 65$ million it pumps annually into the four supercomputer cen- tres to be 'an entitlement programme', say officials. About 10 potential bidders submitted 'concept papers' earlier this month. Final proposals are due in September.

As part of its proposal, UCSD is setting up a network linking all nine campuses of the University of California, as well as the Lawrence Livermore, Lawrence Berkeley and Los Alamos Laboratories which it runs for the Department of Energy, and several state universities.

"I'm very excited about it," says Robert C. Dynes, UCSD's newly designated chancellor. "Potentially, this is the library of the future," he says, referring to the network's information-transmission capabilities as "a blueprint for the nation".

Officials at GA decline to discuss their own proposal. N. Douglas Pewitt, a former government official who has been serving as acting director of the centre since midFebruary, says that the company has submitted a one-page pre-proposal outlining its intentions.

According to observers, the split between GA and UCSD came about because of the nature of the new NSF funding programme. To meet the NSF's goals, UCSD wants to develop an academically led proposal with a broad network of partners, all of whom could capitalize on the use of the supercomputers. But GA saw its role in this model as being reduced merely to that of a computer operator, with limited overall control.

\section{Inquiry clears Canadian researchers}

Ottawa. Three members of the engineering and computer science faculty at Concordia University, Montreal, who were forced out of the university in 1994 on suspicion of alleged financial irregularities, have been cleared after an investigation by the Natural Sciences and Engineering Research Council of Canada (NSERC), and their research grants have been restored.

The investigation found no evidence of misuse of its funds by M. N. S. Swamy, former dean of engineering, T. S. Sankar, then faculty coordinator of research, and Seshadri Sankar, who was director of the Computer Aided Vehicle Engineering Research Centre. The research council has reinstated their research funding at a level that puts them in the top five per cent of awards - provided that they can find eligible research positions.

The inquiry was undertaken after an audit ordered by the university had shown that its administration had permitted the use of NSERC funds for purposes that were not allowed. The three researchers were mentioned in this audit, and this resulted in NSERC's freezing of their research grants and the university's general research grant.

The university then persuaded Swamy and T. S. Sankar to retire early and Seshadri Sankar to resign (see Nature 370, 166; 1996). Concordia itself was required by NSERC to return the missing funds, and to set up new accountability and control mechanisms.

Since then, Swamy has been nominated by his colleagues as emeritus professor, and has again begun to conduct research at Concordia. The new rector, Frederick Lowy, says a return to the faculty by the Sankars is unlikely because of budget restrictions. But he suggests some arrangement may be found to permit them both - as well as Swamy - to resume research.

The Sankars themselves say they are confident the restoration of their research funds will make their attractive candidates for faculty positions at any university requiring their expertise. David Spurgeon
Both Pewitt and UCSD officials claim that they are continuing amicable discussions about a possible future combined bid for one of the new NSF grants. But the chances of such a bid succeeding are uncertain, given the personnel changes and other events of recent weeks.

In February, Sid Karin, the founding director of the centre, who had announced his resignation last autumn but had intended to stay on until 1 May, left GA suddenly to work on UCSD's proposal. Then, in March, GA officials told the university it planned to put in a unilateral bid for the NSF grant.

Shortly afterwards, the second and third most senior officials at the centre - Peter Arzberger and Wayne Pfeiffer - resigned, with Arzberger moving to UCSD's payroll to work on its proposal.

About the same time, GA officials used a ruse to get Karin's long-time secretary who was resigning to join Karin at UCSD - out of her office. The company prevented her from returning, and then took control of her personal computer containing Karin's electronic mail and other information.

Following these events, an attorney representing GA sent Karin a letter that is said to have contained a veiled threat of legal action. Pewitt declines to comment on the letter. But a review of the situation, carried out by a retired GA executive and delivered at the beginning of this month, found that both the letter and efforts to monitor Arzberger's and Karin's e-mail have contributed to a plunge in morale among staff at the centre.

The review concludes that the legal threat was "very negative for the partners". Commenting on potential problems caused by the staff departures, it adds that "the respect they had for (centre) top management is hard to exaggerate".

The review also points out that, if GA moves ahead with its own competing proposal, there are likely to be further staff defections, particularly as the company's solo bid for the NSF contract is seen as having little chance of succeeding.

Richard E. Kaplan, an NSF contract officer for the facility, says he remains concerned that recruitment companies may take advantage of the uncertainty to strip the centre of more talent. "Headhunters are like sharks," he says. "They smell blood in the water."

Such fears were heightened last month when one of the centre's leading scientists - Hans-Werner Braun, a high-speednetwork designer supervising substantial NSF grants - announced he was leaving to work at Teledesic Corporation, a company that is developing a satellite communications system.

Rex Dalton 